\title{
Hume and the Independent Witnesses
}

[This is the accepted version of the paper. The final version appears in Mind 124 (496): 1013-1044. doi: 10.1093/mind/fzv076 available at: http://mind.oxfordjournals.org/content/124/496/1013]

A longstanding and widely accepted objection to the neo-Humean argument concerning miracles is that sufficiently numerous independent testimonies to a miracle should make one almost certain of it. The paper argues that this objection fails. Even witnesses who are known to be (i) sincere (ii) reliable (iii) causally independent of one another and (iv) causally independent of anything relevant other than the supposed miracle itself, might fail to satisfy the very demanding and highly implausible sort of independence that the anti-Humean objection actually requires. Sections 1-5 argue for this claim.

Section 6 turns aside from that argument to investigate conditions under which non-independent witness ensembles should be convincing. Here the conclusion is at best equivocally Humean. There are apparently reasonable doxastic positions in which one should reject even arbitrarily extensive uniform testimony to a miracle. But there may be others in which such testimony is rationally compelling.

\section{The neo-Humean argument}

On a traditional reading, Hume's famous argument against miracles (1777, Ch. X, Pt. I) concludes that human credulity and fallibility being what they are, no testimony can ever make it rational to prefer the hypothesis, that some particular miracle occurred, to the hypothesis that the testimony is itself mistaken. ${ }^{1}$

My interest in this paper is not Hume's actual argument, whatever that may have been, but its modern Bayesian reconstruction (as e.g. in Dawid and Gillies 1989). Let Cr be a probability function reflecting one's degrees of belief. Let $\mathrm{M}$ be a proposition describing some particular miracle. For instance, let M say that at such and such time and place a man weighing about $150 \mathrm{lb}$ walked on liquid water with no other means of support. ${ }^{2}$ Let $t$ be the proposition that some particular eyewitness testified to M. Assume that before any attestation to it one's confidence in $\mathrm{M}$ is very small and also that one's

\footnotetext{
${ }^{1}$ For such a traditional reading see e.g. Broad 1916, pp. 78-80. Recent scholarship has tended to reject this reading. See Fogelin 2003, Ch. 1 and Millican 2011, pp. 171-4.

${ }^{2}$ Throughout, $\mathrm{M}$ is supposed to describe an event whose status as a miracle is not in question: the issue is whether the event did occur, not whether its occurrence is or would have been miraculous.
} 
confidence in a false positive from this witness (i.e. in $\mathrm{t}$ given that $\mathrm{M}$ is false) is much greater:

(1) $\mathrm{Cr}(\mathrm{M})$ is very small

(2) $\mathrm{Cr}(\mathrm{t} \mid \neg \mathrm{M})>>\mathrm{Cr}(\mathrm{M})^{3}$

More informally, (1) says that before hearing the witness one is practically certain that $\mathrm{M}$ is false. For instance, if $\mathrm{M}$ describes the resurrection of Jesus, then (1) says that before hearing reports of it, one is practically certain that Jesus did not rise from the dead (perhaps because one is practically certain that nobody ever did). And (2) says that one is much more confident that the witness would affirm this even if it did not happen, than that it did happen. This may be because one is confident that false witnesses to miracles appear rather often; at any rate, one might very well think that they are much more frequent than actual resurrections.

Two brief comments on (1). First: throughout the following exposition, (1) is the only assumption that relies on the miraculous nature of what $\mathrm{M}$ reports. So it does not matter here, as it may have mattered to Hume himself, whether $M$ is supposed to be the foundation of a system of religion. The neo-Humean argument applies equally to any non-miraculous claim in which one has comparably small credence.

Second: that credence, though small, need not be infinitesimal. Insisting that it was would be too easy a way of setting miracle claims beyond the reach of evidence. ${ }^{4}$ For present purposes a value as big as, say, $\mathrm{Cr}(\mathrm{M})=10^{-50}$ is quite small enough. In fact the illustrative discussion at section 5 gets by on the assumption that $\mathrm{Cr}(\mathrm{M}) \approx 10^{-6}$.

Now on the Bayesian approach adopted here, the rational response to an incoming piece of evidence $\mathrm{E}$ is to update one's confidence in any proposition $\mathrm{H}$ from $\mathrm{Cr}(\mathrm{H})$ to $\mathrm{Cr}$ $(\mathrm{H} \mid \mathrm{E})$. Informally and very roughly, one's new degree of confidence in $\mathrm{H}$, on learning $\mathrm{E}$, should be one's old degree of confidence that if $E$ then $H$.

\footnotetext{
3 '>>' means 'exceeds by a large factor', not 'exceeds by a large difference'.

${ }^{4}$ For instance, Sobel's assumption of infinitesimal probabilities for miracles gives him a very quick response to the anti-Humean argument that this paper discusses (2004, pp. 338-9). Thanks to a referee.
} 
So given the individual positive testimony, one's Bayes-appropriate degree of belief that the miracle has occurred (one's posterior degree of belief in this) is now one's prior $\mathrm{Cr}(\mathrm{M} \mid \mathrm{t})$. And one's Bayes-appropriate posterior that it has not occurred is one's prior $\mathrm{Cr}(\neg \mathrm{M} \mid \mathrm{t})$. So one's correct posterior odds on $\mathrm{M}$, written $\mathrm{O}(\mathrm{M} \mid \mathrm{t})=_{\text {def. }} \mathrm{Cr}(\mathrm{M} \mid \mathrm{t}) /$ $\mathrm{Cr}(\neg \mathrm{M} \mid \mathrm{t})$, is given by:

(3) $\mathrm{O}(\mathrm{M} \mid \mathrm{t})=[\mathrm{Cr}(\mathrm{t} \mid \mathrm{M}) \mathrm{Cr}(\mathrm{M})] /[\mathrm{Cr}(\mathrm{t} \mid \neg \mathrm{M}) \mathrm{Cr}(\neg \mathrm{M})]$

Consider the right hand side of (3). It follows from (1) that this is approximately [Cr $(\mathrm{t} \mid \mathrm{M}) \mathrm{Cr}(\mathrm{M})] / \mathrm{Cr}(\mathrm{t} \mid \neg \mathrm{M})$, from the probability calculus that this quantity is no greater than $\mathrm{Cr}(\mathrm{M}) / \mathrm{Cr}(\mathrm{t} \mid \neg \mathrm{M})$, and from (2) that the latter quantity is very small. Hence the left hand side of (3), one's rational posterior odds on the miracle, should also be very small. So notwithstanding testimony t affirming it, one should remain very confident that $\mathrm{M}$ is false.

This argument depends only on premises (1) and (2), which are reasonable assumptions in any context where we have only a single eyewitness's testimony to a miracle. So it is reasonable to call it an a priori argument against believing such individual testimony.

\section{The Multiple Witnesses Objection}

But what if we have many independent testimonies to a miracle? A well-known argument due to Babbage, Holder and Earman seems to show that independent testimony from enough witnesses must drive one's rational posterior odds in the miracle arbitrarily high (Babbage 1838; Holder 1997, p. 53; Earman 2000, pp. 53-6). ${ }^{5}$ I'll call this the BHE argument. It is as follows.

Index the witnesses $1,2, \ldots i, \ldots \mathrm{N}$. Write $\mathrm{t}^{i}$ for the proposition that witness $i$ testifies to $\mathrm{M}$. Write $\mathrm{T}^{i}$ for $\left(\mathrm{t}^{1} \& \mathrm{t}^{2} \& \ldots \& \mathrm{t}^{i}\right)$. So $\mathrm{T}^{\mathrm{N}}$ says that all of the $\mathrm{N}$ witnesses have testified that the miracle has occurred.

\footnotetext{
${ }^{5}$ I am not, in this paper, going to discuss Holder's and Earman's separate arguments (Holder 1997, pp. 546; Earman 2000, pp. 56-9) concerning multiple witness testimony to distinct events.
} 
In this context, calling the witness testimonies independent involves two types of what is standardly called conditional independence. The first type of conditional independence is this: if one knows that the miracle has occurred, then no amount of (true) positive testimony from any given series of examined witnesses makes any difference to one's confidence that the testimony of the next examined witness is positive. The second type of conditional independence is this: if one knows that the miracle has not occurred then again, no amount of (false) positive testimony from any series of witnesses makes any difference to one's confidence that the testimony of the next witness is positive. ${ }^{6}$

When applied to our witnesses, the two kinds of conditional independence are provably equivalent to the following statements: for any integer $n$ such that $1 \leq n \leq \mathrm{N}$ we have:

(4) Independence of true positives (ITP): $\mathrm{Cr}\left(\mathrm{T}^{n} \mid \mathrm{M}\right)=\prod_{1 \leq i \leq n} \mathrm{Cr}\left(\mathrm{t}^{i} \mid \mathrm{M}\right)$

\section{(5) Independence of false positives (IFP): $\mathrm{Cr}\left(\mathrm{T}^{n} \mid \neg \mathrm{M}\right)=\prod_{1 \leq i \leq n} \mathrm{Cr}\left(\mathrm{t}^{i} \mid \neg \mathrm{M}\right)$}

Roughly, ITP says that positive testimonies of the several witnesses are uncorrelated given the miracle has occurred. IFP says that their positive testimonies are uncorrelated given that the miracle has not occurred. Both claims are crucial to the argument. ${ }^{7}$

\footnotetext{
${ }^{6}$ It is crucial that independence here really be conditional independence as stated, and not unconditional independence. We do not require that the probability of any one witness's being right is independent of that of any other witness's being right (i.e. conditional on nothing). Peirce criticized Hume on just this point, since he took Hume to be saying (inter alia) that if each witness has a probability $p$ of being right, then their uniformly positive testimonies would if unconditionally independent transmit a probability of $p^{\mathrm{N}}$ to the miracle (Peirce 1901, para. 7.165). Of course that method leads to absurd results, for illustration of which see Merrill 1991, pp. 104-12. But whether or not the method was Hume's it certainly is not neo-Hume's.

Nevertheless, one of Peirce's criticisms of Hume has an echo in the present paper. Peirce argued that in cases of historical interest - not necessarily to do with miracles-the unconditional objective probabilistic independence of sources is simply implausible, inter alia because ' $[\mathrm{t}] \mathrm{he}$ same circumstances which lead one witness into error are likely to operate to deceive another' (1901, para. 7.176). The argument in sect. 4 pursues that point and attempts to quantify its bearing. But its setting and its tendency could hardly be less Peircean, for here the target is conditional subjective probabilistic independence, and the point of attacking it is to vindicate Hume's anti-religious conclusion, not to undermine his general historical method.

${ }^{7}$ It is easy to see that (4) and (5) follow from Earman's version of the independence claim (2000, p. 55). Earman in fact makes the stronger assumption that the factorization in (4) and (5) applies to any combination of positive and negative testimonies on the hypothesis that the miracle occurred and also on the hypothesis that it did not. But his argument relies only upon consequences of it that are equivalent to (4) and (5). Note that Earman's version also conditionalizes on the subject's background knowledge $\mathrm{K}$ and
} 
Now assume for simplicity that all witnesses are equally reliable. Assume further that they are reliable in the undemanding sense that each is more likely to give a true positive report if the miracle has occurred than to give a false positive report if it has not. And assume a prior on which (quite reasonably) these probabilities of true and false positives are non-extreme; I'll label them $p$ and $q$. So for any index $i$ we have:

(6) $p==_{\text {def. }} \operatorname{Cr}\left(\mathrm{t}^{i} \mid \mathrm{M}\right)$

(7) $q==_{\text {def. }} \mathrm{Cr}\left(\mathrm{t}^{i} \mid \neg \mathrm{M}\right)$

(8) $1>p>q>0$

Let us now work out the posterior odds on the miracle $\mathrm{O}\left(\mathrm{M} \mid \mathrm{T}^{\mathrm{N}}\right)$ given all of the $\mathrm{N}$ positive testimonies to it. By the same idea as that behind (3) we have:

(9) $\mathrm{O}\left(\mathrm{M} \mid \mathrm{T}^{\mathrm{N}}\right)=\mathrm{O}$ (M) $\mathrm{Cr}\left(\mathrm{T}^{\mathrm{N}} \mid \mathrm{M}\right) / \mathrm{Cr}\left(\mathrm{T}^{\mathrm{N}} \mid \neg \mathrm{M}\right)$

course of experience E (2000, p. 26). But these terms play no role in the present discussion, so I'll suppress them.

It is also easy to see that (4) and (5) are each equivalent to the two kinds of conditional independence as I introduced them, viz.:

(i) $\quad \forall i\left(\mathrm{Cr}\left(\mathrm{t}^{i} \mid \mathrm{T}^{i-1} \& \mathrm{M}\right)=\mathrm{Cr}\left(\mathrm{t}^{i} \mid \mathrm{M}\right)\right)$

(ii) $\quad \forall i\left(\mathrm{Cr}\left(\mathrm{t}^{i} \mid \mathrm{T}^{i-1} \& \neg \mathrm{M}\right)=\mathrm{Cr}\left(\mathrm{t}^{i} \mid \neg \mathrm{M}\right)\right)$

I'll prove the equivalence of (i) and (4); the proof that (ii) and (5) are equivalent is exactly parallel. First suppose that (4) is true and take an arbitrary $i$. Then:

(iii) $\quad \operatorname{Cr}\left(\mathrm{t}^{i} \mid \mathrm{T}^{i-1} \& \mathrm{M}\right)=\mathrm{Cr}\left(\mathrm{T}^{i} \mid \mathrm{M}\right) / \mathrm{Cr}\left(\mathrm{T}^{i-1} \mid \mathrm{M}\right)$; so

(iv) $\quad \operatorname{Cr}\left(\mathrm{t}^{i} \mid \mathrm{T}^{i-1} \& \mathrm{M}\right)=\mathrm{Cr}\left(\mathrm{t}^{i} \mid \mathrm{M}\right)$ by (iii) and (4)

Now assume that (i) is true and take an arbitrary $n$. Then:

(v) $\quad \operatorname{Cr}\left(\mathrm{T}^{n} \mid \mathrm{M}\right)=\mathrm{Cr}\left(\mathrm{T}^{n-1} \& \mathrm{t}^{n} \mid \mathrm{M}\right)$; so

(vi) $\quad \operatorname{Cr}\left(\mathrm{T}^{n} \mid \mathrm{M}\right)=\mathrm{Cr}\left(\mathrm{t}^{n} \mid T^{n-1} \& \mathrm{M}\right) \mathrm{Cr}\left(\mathrm{T}^{n-1} \mid \mathrm{M}\right)$ by (v)

(vii) $\quad \operatorname{Cr}\left(\mathrm{T}^{n} \mid \mathrm{M}\right)=\mathrm{Cr}\left(\mathrm{t}^{n} \mid \mathrm{M}\right) \mathrm{Cr}\left(\mathrm{T}^{n-1} \mid \mathrm{M}\right)$ by (i), (vi)

(4) then follows straightforwardly by (vii) and induction on $n$. 
—where ' $\mathrm{O}(\mathrm{M})$ ' denotes one's odds on $\mathrm{M}$ i.e. $\mathrm{Cr}(\mathrm{M}) / \mathrm{Cr}(\neg \mathrm{M})$. It follows from (4), (5) and (9) that:

$$
\mathrm{O}\left(\mathrm{M} \mid \mathrm{T}^{\mathrm{N}}\right)=\mathrm{O}(\mathrm{M}) \prod_{1 \leq i \leq \mathrm{N}} \mathrm{Cr}\left(\mathrm{t}^{i} \mid \mathrm{M}\right) / \prod_{1 \leq i \leq \mathrm{n}} \mathrm{Cr}\left(\mathrm{t}^{i} \mid \neg \mathrm{M}\right)
$$

It follows from (6), (7) and (10) that:

$$
\mathrm{O}\left(\mathrm{M} \mid \mathrm{T}^{\mathrm{N}}\right)=\mathrm{O}(\mathrm{M})(p / q)^{\mathrm{N}}
$$

And it follows from (8) and (11) that however small one's prior odds on the miracle $\mathrm{O}$ (M), increasing $\mathrm{N}$ can drive one's posterior odds on it arbitrarily high.

In English, (9) is saying that one's confidence in a miracle $M$ given all this testimony to it will be greater if one thinks that this testimony is much more unlikely to have appeared if $\mathrm{M}$ had been false than if $\mathrm{M}$ had been true. And the argument for (11) demonstrates that one should think that the testimony is much more unlikely to have appeared if $\mathrm{M}$ had been false than if $\mathrm{M}$ had been true. If $\mathrm{M}$ had been false then all of these witnesses would have to have been making a mistake about what they saw. Given that each witnesses is more likely to get $M$ right than to get it wrong, it is, for large enough $\mathrm{N}$, vastly more unlikely that they all get it wrong than that they all get it right.

And so Babbage concluded that:

[I]f independent witnesses can be found, who speak truth more frequently than falsehood, it is ALWAYS possible to assign a number of independent witnesses, the improbability of the falsehood of whose concurring testimony shall be greater than that of the improbability of the miracle itself. $(1838, \text { p. } 212)^{8}$

\footnotetext{
derivable from our premises:

(i) $\quad \mathrm{Cr}\left(\mathrm{T}^{\mathrm{N}} \& \neg \mathrm{M}\right)=\mathrm{Cr}(\neg \mathrm{M}) \prod_{1 \leq i \leq \mathrm{N}} \mathrm{Cr}\left(\mathrm{t}^{i} \mid \neg \mathrm{M}\right)$ by (5)

(ii) $\quad \mathrm{Cr}\left(\mathrm{T}^{\mathrm{N}} \& \neg \mathrm{M}\right)=q^{\mathrm{N}} \mathrm{Cr}(\neg \mathrm{M})$ by (i), (10)

(iii) $\quad \exists \mathrm{N}>0 \mathrm{Cr}(\mathrm{M})>\mathrm{Cr}\left(\mathrm{T}^{\mathrm{N}} \& \neg \mathrm{M}\right)$ by (ii), (8)
}

${ }^{8}$ What Babbage says is not exactly what has been proven here. In current terms his claim is that there is some $\mathrm{N}$ such that $1-\mathrm{Cr}\left(\mathrm{T}^{\mathrm{N}} \& \neg \mathrm{M}\right)>1-\mathrm{Cr}(\mathrm{M})$ i.e. such that $\mathrm{Cr}(\mathrm{M})>\mathrm{Cr}\left(\mathrm{T}^{\mathrm{N}} \wedge \neg \mathrm{M}\right)$. But it is easily 
We do not even require that the witnesses be highly reliable or skeptical: so long as they 'speak the truth more often than falsehood' (so that $p>q$ ), some number $\mathrm{N}$ of them ought still be enough to convince even an initially skeptical auditor.

If Babbage is right, then where did Hume, or 'neo-Hume', go wrong? Nothing in the objection casts any doubt either upon (3) itself-which is an identity of the probability calculus - or upon the conclusion that the posterior odds that it mentions are inevitably negligible. The problem is that this no longer matters. Let Hume be right that no one testimony should convince anyone of a miracle. Still there is nothing in principle limiting the number of testimonies to just one.

Indeed it is hardly the usual case in practice. St Paul implies more than 500 witnesses to the central miracle of Christianity (I Cor. 15: 3-9). And part II of Hume's own essay relates this story of the Cardinal de Retz:

When that intriguing politician fled into Spain, to avoid the persecution of his enemies, he passed through Saragossa, the capital of Arragon, where he was shewn, in the cathedral, a man, who had served seven years as a doorkeeper, and was well known to every body in town, that had ever paid his devotions at that church. He had been seen, for so long a time, wanting a leg; but recovered that limb, by the rubbing of holy oil upon the stump; and the cardinal assures us that he saw him with two legs. This miracle was vouched by all the canons of the church; and the whole company in town were appealed to for a confirmation of the fact; whom the cardinal found, by their zealous devotion, to be thorough believers of the miracle. Here the ... witnesses [were] very numerous, and all of them, in a manner, spectators of the fact, to which they gave their testimony. (Hume 1777, pp. 123-4)

On the other hand although (iii) is what Babbage says, it is not exactly to the point. What is relevant is not (iii) that for some $\mathrm{N}$ the falsity of $\mathrm{N}$ independent testimonies to $\mathrm{M}$ should be more unlikely than $\mathrm{M}$, but (iv) that for some $\mathrm{N}$ the falsity of $\mathrm{N}$ independent testimonies to $\mathrm{M}$ should be more unlikely than their truth, for it is (iv) and not (iii) that relates the relative credences that we should put in $\mathrm{M}$ and $\neg \mathrm{M}$ given multiple witnesses to $M$.

In any case the points in this paper apply to Babbage's original argument as much as to the present version of it, since both rely on the crucial independence claim (5). 
If Babbage is right then Hume's argument applies only to cases involving a single witness; but neither in theory nor in practice do such cases have great interest. The BHE argument therefore conflicts directly with Hume's claim to have 'discovered an argument... which, if just, will, with the wise and learned, be an everlasting check to all kinds of superstitious delusion, and consequently, will be useful as long as the world endures' (1777, p. 109); and the same can be said of any neo-Humean pretension to that title.

\section{The Earman / Millican debate}

More recent commentators than Babbage have accepted the objection: as we have seen, both Holder (1998, p. 53) and Earman (2002, p. 100-2) consider it telling. Even Mackie and Sober, who are more sympathetic to Hume's overall stance, both acknowledge that it presents a genuine threat to Hume's conclusion: thus Sober, for instance, writes that 'what one imperfect witness cannot do, a number of such witnesses can easily achieve' (2004, p. 491; cf. Mackie 1982, pp. 25-6). ${ }^{9}$

The only modern writers ${ }^{10}$ to explore possible neo-Humean responses are Millican and (ironically) Earman himself, who writes that it may be possible in particular cases to question the independence assumption:

The fact that many self-confessed alien abductees draw similar pictures of their captors and tell similar stories about invasive examinations of their bodies is to me not evidence in favour of alien abductions but rather evidence of the pervasive influence of media stories and television documentaries. (2000, p. 60)

But this is plainly not enough to rescue the neo-Humean argument, which was supposed to be both a priori and widely applicable. The neo-Humean must show that there is some problem with the 'alien abduction' stories that is not specific to them but which arises in

\footnotetext{
${ }^{9}$ Jantzen (2012, p. 32) also expresses sympathy with the BHE argument, although his main aim in that paper is to discredit the Bayesian approach itself on broadly Peircean grounds. Those issues lie beyond the scope of this paper.

${ }^{10}$ Here setting aside Sobel's brief discussion (1984, pp. 338-9) for a reason that I mention at n. 4 and in the accompanying main text.
} 
principle for any attempt to establish supernatural events through multiple attestation. On this point Earman makes no concession:

I would certainly admit — and argue that Hume would have to admit — that there is nothing in principle impossible about arranging circumstances where the requisite independence conditions are satisfied for witnesses to (alleged) alien abductions or for that matter to (alleged) religious miracles. (2000, p. 60; cf. Earman 2002, p. 102)

I have only seen one other challenge to the argument: this appears in two papers of Millican's $(2003,2013)$ that include the most penetrating analyses of the problem. Millican summarizes their essential point as follows:

Without contesting Earman's technical results, one can dispute the seriousness of this ... issue since most of his discussion seems to ignore entirely the epistemological dimension of how one could possibly know that the witnesses in question are genuinely independent. (2003, p. 20 n. 34)

Given my own interpretation of 'independence' as the conjunction of ITP and IFP, this looks irrelevant. Recall that ITP (IFP) constrains one's beliefs: it says that one's confidence in any run of $\mathrm{N}$ positive testimonies given that the miracle has (has not) occurred is simply the product of one's confidences in each individual positive testimony, given that the miracle has (has not) occurred. But if this is what independence is, then as long as it obtains, why does it matter that one knows that it does? More formally: the argument for (11) goes through as long as (4) and (5) are true. And as long as (11) is true, an observer of enough uniform positive testimony will if rational get arbitrarily close to certainty of $\mathrm{M}$, whether or not he or anyone else knows this.

But properly understood, Millican's point is beyond the scope of this response, because the 'independence' that he means doesn't describe the observer's beliefs but rather the actual causal structure of the situation. Thus in the later paper he explains 'independence' to mean what I'll call: 
(12) True independence: the witnesses are not colluding or subject to any other common influence except for their perception of $\mathrm{M}$ itself (or its absence) (Millican 2013, p. 281) ${ }^{11}$

I propose to interpret 'colluding' here very broadly, so as to include all forms of causal influence of one testimony upon another. So true independence excludes not only ordinary conscious collusion between witnesses but also e.g. the accidental overhearing by one witness of another's testimony. So understood, true independence is simply the claim that in fact the witnesses' testimonies are causally dependent on their perception of M (or whatever they mistook for it) but not on either (a) one another or (b) any common cause of the testimony other than $\mathrm{M}$ (or what they mistook for it). ${ }^{12}$

Millican's point is then that for the BHE argument to apply one must know that true independence holds. In the present, relatively subjective Bayesian environment, that claim had better be understood as follows: if the BHE argument is sound then one must be certain of true independence.

Is that conditional true? Strictly speaking it is false: the premises ITP and IFP (i.e. (4) and (5)) are consistent with certainty that true independence does not hold. For instance, suppose one knows the following: (a) each witness hears every previous witness's testimony; (b) some proportion $s$ of the witnesses are falsehood-suggestible: if $\mathrm{M}$ is false, hearing uniform positive testimony from all previous witnesses raises their own chance of giving positive testimony from $q$ to $q_{1}>q$; otherwise this chance is q; (c) the remaining proportion $1-s$ of witnesses are falsehood-countersuggestible: if $\mathrm{M}$ is false, hearing uniform positive testimony from all previous witnesses lowers their chance of giving positive testimony to $q_{2}<q$; otherwise again this chance is $q$. Certainty of (a)(c) is inconsistent with certainty of true independence, because certainty of (a) is inconsistent with certainty of true independence. And yet for a suitable choice of $q_{1}, q_{2}$

\footnotetext{
${ }^{11}$ But 'true independence' is my own label. Here and in a few other places, I'll use $M$ to denote the miraculous event itself, and not, as elsewhere, to abbreviate a proposition describing it. The intention should be clear from the context.

${ }^{12}$ This is also how Bovens and Hartmann informally characterize independence (2003, p. 70), explicitly for the case of witnesses to different facts but also (at Ch. 5) implicitly to cases where (as here) many witnesses confirm the same story. A similar characterization is implicit in Kruskal 1988.
} 
and $s$ the crucial premises ITP and IFP still hold, and so the BHE argument goes through. ${ }^{13}$

But setting aside this rather fanciful case, plausible reasons for doubting true independence in real-life cases probably would also undermine IFP or ITP. I have in mind suspicions of intratestimonial influence of the sort that Hume himself describes in the second, psychological part of the essay. For instance, suppose that one seriously entertains the possibility that many of the later witnesses to testify are in fact repeating or elaborating stories that originate from other witnesses, because they have a desire to attract the attention and interest of others by relating these things as if they saw them (Hume 1777, pp. 117-19). In this case one is uncertain of true independence because one suspects that earlier testimony influences later testimony. But one's reason for suspecting this also falsifies IFP, since a run of false positives would increase one's confidence in these influences and so lead one to expect further false positives. And as Hume points out, many actual miracle stories do concern times and places of which we

\footnotetext{
${ }^{13}$ More formally: let $S_{n}$ be the hypothesis that the $n$th witness to testify is falsehood-suggestible (so $\neg S_{n}$ says that she is falsehood-countersuggestible). Choose $q=0.2, q_{1}=0.3, q_{2}=0.1$ and $\mathrm{s}=0.5$. Suppose further (d) that the proportions of suggestible and countersuggestible witnesses amongst those who are yet to testify is the same, whether or not $\mathrm{M}$ is true and however many positive testimonies we already have; (e) that suggestibility and countersuggestibility only operate if $\mathrm{M}$ is false; if $\mathrm{M}$ is true then each witness has a fixed and common chance $p$ of testifying positively. Then for any $i, n \geq 2$ we have:$$
\mathrm{Cr}\left(\mathrm{T}^{i} \mid \mathrm{T}^{i-1} \& \neg \mathrm{M}\right)=\mathrm{Cr}\left(\mathrm{T}^{i} \mid \mathrm{T}^{i-1} \& \mathrm{~S}_{i} \& \neg \mathrm{M}\right) \mathrm{Cr}\left(\mathrm{S}_{i} \mid \mathrm{T}^{i-1} \& \neg \mathrm{M}\right)+\mathrm{Cr}\left(\mathrm{T}^{i} \mid \mathrm{T}^{i-1} \& \neg \mathrm{S}_{i} \wedge\right.
$$
$\neg \mathrm{M}) \mathrm{Cr}\left(\neg \mathrm{S}_{i} \mid \mathrm{T}^{i-1} \wedge \neg \mathrm{M}\right)$ by the probability calculus

(ii) $\quad \operatorname{Cr}\left(\mathrm{T}^{i} \mid \mathrm{T}^{i-1} \& \neg \mathrm{M}\right)=\mathrm{Cr}\left(\mathrm{T}^{i} \mid \mathrm{T}^{i-1} \& \mathrm{~S}_{i} \& \neg \mathrm{M}\right) \mathrm{Cr}\left(\mathrm{S}_{i}\right)+\mathrm{Cr}\left(\mathrm{T}^{i} \mid \mathrm{T}^{i-1} \& \mathrm{~S}_{i} \& \neg \mathrm{M}\right) \mathrm{Cr}\left(\neg \mathrm{S}_{\mathrm{i}}\right)$ by (i) and (d)

(iii) $\quad \operatorname{Cr}\left(\mathrm{T}^{i} \mid \mathrm{T}^{i-1} \& \neg \mathrm{M}\right)=s \mathrm{Cr}\left(\mathrm{t}^{i} \mid \mathrm{T}^{i-1} \& \mathrm{~S}_{i} \& \neg \mathrm{M}\right)+(1-s) \mathrm{Cr}\left(\mathrm{t}^{i} \mid \mathrm{T}^{i-1} \& \mathrm{~S}_{i} \& \neg \mathrm{M}\right)$ by (ii), (b), (c) and the definition of $\mathrm{T}^{i}, \mathrm{t}^{i}$

(iv) $\quad \operatorname{Cr}\left(\mathrm{T}^{i} \mid \mathrm{T}^{i-1} \wedge \neg \mathrm{M}\right)=s q_{1}+(1-s) q_{2}=q$ by (iii), (a), (b), (c) and the stipulated values of $q$, $q_{1}, q_{2}$ and $s$

(v) $\quad \operatorname{Cr}\left(\mathrm{T}^{n} \mid \neg \mathrm{M}\right)=\mathrm{Cr}\left(\mathrm{t}^{1} \mid \neg \mathrm{M}\right) \prod_{2 \leq j \leq n} \mathrm{Cr}\left(\mathrm{T}^{j} \mid \mathrm{T}^{j-1} \wedge \neg \mathrm{M}\right)$ by definition of $\mathrm{T}^{n}$

(vi) $\quad \operatorname{Cr}\left(\mathrm{T}^{n} \mid \neg \mathrm{M}\right)=\mathrm{Cr}\left(\mathrm{t}^{1} \mid \neg \mathrm{M}\right) \mathrm{q}^{n-1}$ by (v) and generalization on (iv)

(vii) $\quad \mathrm{Cr}\left(\mathrm{t}^{i} \mid \neg \mathrm{M}\right)=\mathrm{Cr}\left(\mathrm{t}^{i} \mid \neg \mathrm{M} \& \mathrm{~T}^{i-1}\right) \mathrm{Cr}\left(\mathrm{T}^{i-1} \mid \neg \mathrm{M}\right)+\mathrm{Cr}\left(\mathrm{t}^{i} \mid \neg \mathrm{M} \& \neg \mathrm{T}^{i-1}\right) \mathrm{Cr}\left(\neg \mathrm{T}^{i-1} \mid \neg \mathrm{M}\right)$ by the probability calculus

(viii) $\quad \operatorname{Cr}\left(\mathrm{t}^{i} \mid \neg \mathrm{M} \& \mathrm{~T}^{i-1}\right)=\mathrm{Cr}\left(\mathrm{t}^{i} \mid \neg \mathrm{M} \& \mathrm{~T}^{i-1} \& \mathrm{~S}_{i}\right) \mathrm{Cr}\left(\mathrm{S}_{i} \mid \neg \mathrm{M} \& \mathrm{~T}^{i-1}\right)+\mathrm{Cr}\left(\mathrm{t}^{i} \mid \neg \mathrm{M} \& \mathrm{~T}^{i-1} \&\right.$ $\left.\neg \mathrm{S}_{i}\right) \mathrm{Cr}\left(\neg \mathrm{S}_{i} \mid \neg \mathrm{M} \& \mathrm{~T}^{i-1}\right)$ by the probability calculus

(ix) $\quad \operatorname{Cr}\left(\mathrm{t}^{i} \mid \neg \mathrm{M} \& \mathrm{~T}^{i-1}\right)=s q_{1}+(1-s) q_{2}=q$ by (viii), (a), (b), (c) and the stipulated values of $q, q_{1}, q_{2}$ and $s$.

(x) $\quad \operatorname{Cr}\left(\mathrm{t}^{i} \mid \neg \mathrm{M} \& \neg \mathrm{T}^{i-1}\right)=q$ by (b) and (c)

(xi) $\quad \mathrm{Cr}\left(\mathrm{t}^{i} \mid \neg \mathrm{M}\right)=q$ by (vii), (ix), (x)

(xii) $\quad \operatorname{Cr}\left(\mathrm{T}^{n} \mid \neg \mathrm{M}\right)=\prod_{1 \leq i \leq n} \mathrm{Cr}\left(\mathrm{t}^{i} \mid \neg \mathrm{M}\right)$ by (vi) and generalization on (xi)
}

This proves IFP; and ITP follows straightforwardly from (e). So IFP and ITP can hold even if, as in this case, one knows that true independence fails. 
entertain this type of suspicion. Indeed 'not only in remote and barbarous times, but also in recent ones, we are usually justified in suspecting that what look like distinct reports of a remarkable occurrence arise from different strands of a single tradition between which there has already been communication' (Mackie 1982, p. 26; cf. Millican 2013, p. 281).

So as Millican says, there are genuine practical obstacles to independence assumptions that the BHE argument really needs. And they are likely to press anyone who wishes to apply that argument to any actual collection of testimonies to miracles, many of which are so ancient that we simply cannot rule out that some witnesses heard the stories from others. Indeed in real life, as the number of witnesses increases, the difficulty of establishing their true independence might very well increase, or one's confidence in their true independence might fall, so quickly as to undercut any additional credibility that their testimony gets from their number. ${ }^{14}$

But rather than pursue this point, I will argue that even if Earman et al. could answer it, it would do them no good. Setting aside practical questions about whether and in what circumstances true independence is feasibly knowable, I turn-in the spirit of Part I of Hume's essay - to a more theoretical point. Let us grant Earman that true independence is as certain as it could ever get. I now argue that even then, the premises of the BHE argument are implausible.

\section{Projectibility in the Panopticon}

To that end, waive all 'merely' practical concerns and imagine a situation where causal independence between testimonies, and also between any individual testimony and any common source other than $\mathrm{M}$, obtains if it ever does.

Bentham's 'Panopticon' - originally a model for a prison — consists of a central observation tower surrounded by a circle of N prison cells. Sitting atop the tower, the warden can see and communicate with all of the prison cells, but no prisoner can see or communicate with any other prisoner (Bentham 1791). ${ }^{15}$ More benignly, replace the

\footnotetext{
${ }_{15}^{14}$ Thanks to a referee for this point.

15 The original plan also required that none of the prisoners be able to observe the warden; this was supposed to be achieved by a system of blinds that would have to be removed for the present purpose. Perhaps the closest thing to a real-life Panopticon is the Presidio Modelo in Cuba.
} 
observation platform with a large stage that can be seen from each cell; but still none of the cells communicates with any other. Some self-proclaimed prophet has forecast a miracle on this stage at a specific date and time. In each cell we place a witness possessed of skepticism, integrity, sincerity and general good sense; the witnesses have never been in direct or mediated contact of any sort. In each cell are a pencil and a pad. We ask each witness to observe the stage at the time in question, to write down what happened on it, and then to depart leaving the report in the cell, which automatically locks behind her. We later collect the reports, and it turns out that each one is to the effect that a man weighing about $150 \mathrm{lb}$ walked across the surface of a large tank of liquid water without any other means of support.

It's not really clear what more anyone could do to arrange for true independence; not clear, therefore, how one could ever get closer to certainty that this condition holds. So doesn't this arrangement also suffice for independence in the sense of (4) and (5)?

In fact it does not; moreover neither (4) ITP nor (5) IFP are generally attainable - at any rate for the human witnesses at which neo-Hume's argument is directed. (Physical evidence is a different matter: see sect. 5.) The reason is that both forms of independence are incompatible with the fact that any class of human testimonies has properties that I'll call true-positive and false-positive projectibility, defined as follows:

(13) Projectibility: Let $\mathrm{Cr}$ be a probability function and let $\mathrm{T}=\left\{\mathrm{t}^{1}, \mathrm{t}^{2}, \ldots \mathrm{t}^{\mathrm{N}}\right\}$ be a set of propositions recording a collection of testimonies to a proposition $\mathrm{M}$; write $\mathrm{T}^{j}=\mathrm{t}^{1} \& \mathrm{t}^{2} \& \ldots \& \mathrm{t}^{j}$. Then:

(a) $\mathrm{T}$ is true-positive projectible (with respect to $\mathrm{M}$ and $\mathrm{Cr}$ ) iff for any $j$ s.t. $2 \leq j \leq \mathrm{N}: \operatorname{Cr}\left(\mathrm{t}^{j} \mid \mathrm{T}^{j-1} \& \mathrm{M}\right)>\mathrm{Cr}\left(\mathrm{t}^{j} \mid \mathrm{M}\right)$

(b) $\mathrm{T}$ is false-positive projectible (with respect to $\mathrm{M}$ and $\mathrm{Cr}$ ) iff for any $j$ s.t. $2 \leq j \leq \mathrm{N}: \operatorname{Cr}\left(\mathrm{t}^{j} \mid \mathrm{T}^{j-1} \& \neg \mathrm{M}\right)>\mathrm{Cr}\left(\mathrm{t}^{j} \mid \neg \mathrm{M}\right)$

Intuitively, the meaning of true-positive projectibility is that the more credulity one finds in face of a true miracle, the more one expects. And the meaning of false-positive 
projectibility is that the more credulity one finds in face of a pretended miracle, the more one expects. More specifically, true-positive (false-positive) projectibility means that if one knows that the miracle has (resp. has not) occurred then one will take uniformly positive testimony from every so-far examined witness to be additional grounds for expecting positive testimony from the next one.

It is worth emphasizing that projectibility of either type is a form of conditional probabilistic dependence. It is a familiar fact that unconditional probabilistic dependence is entirely compatible with the sorts of conditional probabilistic independence that the BHE argument demands. For instance, the testimonies of successive witnesses are certainly unconditionally dependent relative to one's credence function: if one doesn't know whether $M$ is true, each successive testimony to it will increase one's confidence that the next witness will also testify positively, because it will increase (perhaps ever so slightly) one's confidence that $\mathrm{M}$ is true. This unconditional form of dependence poses no threat to ITP or IFP, which are as I said forms of conditional independence.

But projectibility is a matter of conditional dependence. It says that one's credences are such that: even if one knows that the miracle has occurred, or even if one knows that it has not, successive positive testimonies will still increase one's confidence that the next testimony will also be positive. What I am now going to argue is that projectibility is (a) plausible even in the Panopticon and (b) inconsistent with the conditional independence premises of the BHE argument.

(a) Is the testimony of human witnesses to a miracle true-positive projectible or false-positive projectible with respect to a reasonable subjective distribution $\mathrm{Cr}$ ? It is plausible that in general collections of eyewitness testimonies should be both truepositive and false-positive projectible.

Consider first false-positive projectibility. Suppose you know that what happened in the Panopticon is an illusion. (To make it vivid, suppose that you are the illusionist.) After the trick is over you read the separate witness reports. Initially-i.e. before reading them-you have some subjective distribution over how convincing the illusion was i.e. over how likely each witness was to have been fooled.

But now suppose it's clear from each report that its author was fooled. Each of them writes something like this: 'It wasn't a trick at all! He really did walk on water!' 
Every time you read such a report you will, I claim quite reasonably, become a little more confident in the quality of the illusion, and so also a little more confident that the next witness whose report you read will also have been fooled.

In other words, if you know that $\neg \mathrm{M}$, then the longer any run of witnesses who believe that $\mathrm{M}$, the more confident you are that the next witness is also such a dupe. It follows that your initial credence function satisfies $\operatorname{Cr}\left(\mathrm{t}^{j} \mid \mathrm{T}^{j-1} \& \neg \mathrm{M}\right)>\mathrm{Cr}\left(\mathrm{t}^{j} \mid \neg \mathrm{M}\right)$ for each integer $j$ between 2 and $\mathrm{N}$. That establishes false-positive projectibility in this case; and if it applies in the Panopticon then the argument seems also to apply to any multiple witnessing of a 'miracle' that might be relevant to neo-Humean concerns. (I shall return to this point at sect. 5.)

A similar argument supports true-positive projectibility. Suppose this time that you are for some (perhaps very good) reason convinced of your own ability to walk on water. Of course you know first-hand of the skepticism with which many people greet even miracles that they see for themselves. 'There must have been some trickery' has in the past been a regrettably common response to your works even amongst those who had no idea what the trick might have been. Only a truly vivid and transparent display of your powers will overcome the most hardened skeptics. Initially-i.e. before reading the reports-you again have some subjective credential distribution over the effectiveness, in that connection, of this latest miracle.

Now suppose that one by one each report enthusiastically agrees that it was a miracle: 'It's amazing, he really did walk on water!' Each such report will, I claim, make you quite reasonably a little more confident in the vividness of the miracle, and so also a little more confident that the author of the next report that you read will also have seen the light.

In other words, if you know that $\mathrm{M}$ then the longer the run of true believers that you observe, the more confident you are that the next witness is also a true believer. It follows that your initial credence function satisfies $\mathrm{Cr}\left(\mathrm{t}^{j} \mid \mathrm{T}^{j-1} \& \mathrm{M}\right)>\mathrm{Cr}\left(\mathrm{t}^{j} \mid \mathrm{M}\right)$ for each integer $j$ between 2 and $\mathrm{N}$. That establishes true-positive projectibility in this case; and again, the argument seems also to apply to any other plausible and relevant case of multiple testimonies. 
Here is a crude model of how false-positive projectibility might rationally arise. (Exactly parallel points apply to true-positive projectibility.) Suppose that each witness has some objective chance of being fooled by an illusion purporting to be $\mathrm{M}$ (these chances might be different for each witness). And suppose that for each witness $j$, you don't know the objective chance of that witness's delivering positive testimony given $\neg \mathrm{M}$, but you do have unconditional and conditional cumulative probability distributions $\mathrm{F}^{j}$ and $\mathrm{F}_{\neg \mathrm{M}}^{j}$ for that chance, defined as follows:

$$
\begin{aligned}
& \mathrm{F}^{j}(x)={ }_{\text {def. }} \operatorname{Cr}\left(\operatorname{Ch}\left(\mathrm{t}^{j} \mid \neg \mathrm{M}\right) \leq x\right), 0 \leq x \leq 1 \\
& \mathrm{~F}_{\neg \mathrm{M}}^{j}(x)=_{\text {def. }} \operatorname{Cr}\left(\operatorname{Ch}\left(\mathrm{t}^{j} \mid \neg \mathrm{M}\right) \leq x \mid \neg \mathrm{M}\right), 0 \leq x \leq 1
\end{aligned}
$$

So (14) defines (e.g.) $\mathrm{F}^{j}(0.5)$ as your confidence that witness $j$ has a no greater than $50 \%$ chance of being fooled by an illusion. And (15) defines (e.g.) $\mathrm{F}_{\neg \mathrm{M}}^{j}(0.5)$ as your confidence that witness $j$ has a no greater than $50 \%$ chance of being fooled by an illusion, given that what happened on stage was an illusion.

Now suppose that given $\neg \mathrm{M}$, uniform positive testimony from the first $j-1$ witnesses raises your estimate of this conditional chance $\mathrm{Ch}\left(\mathrm{t}^{j} \mid \neg \mathrm{M}\right)$ in the following sense: for any $x \in(0,1)$, you are strictly less confident than before that this chance is no greater than $x$. In other words, and writing $\mathrm{F}_{\neg \mathrm{M}}^{j}\left(x \mid \mathrm{T}^{j-1}\right)=_{\text {def. }} \mathrm{Cr}\left(\mathrm{Ch}\left(\mathrm{t}^{j} \mid \neg \mathrm{M}\right) \leq x \mid \neg \mathrm{M} \&\right.$ $\mathrm{T}^{j-1}$ ), we are supposing that:

$$
\mathrm{F}_{\neg \mathrm{M}}^{j}(x)>\mathrm{F}_{\neg \mathrm{M}}^{j}\left(x \mid \mathrm{T}^{j-1}\right), 0<x<1
$$

That is, (16) says that $\mathrm{F}_{\neg \mathrm{M}}^{j}\left(x \mid \mathrm{T}^{j-1}\right)$ strictly first-order stochastically dominates $\mathrm{F}_{\neg \mathrm{M}}^{j}(x)$. And if this holds for all $j$, then it follows straightforwardly that false-positive projectibility holds with respect to $\mathrm{M}$ and $\mathrm{Cr}^{16}$

\footnotetext{
${ }^{16}$ Assume the conditional version of the Principle Principal connecting credence and objective chance (Joyce 1999, p. 166), which in the present context implies (i) and (ii) below:

(i) $\quad \operatorname{Cr}\left(\mathrm{t}^{j} \mid \neg \mathrm{M}\right)=\int_{0 \leq x \leq 1} x \mathrm{dF}$

(ii) $\quad \mathrm{Cr}\left(\mathrm{t}^{j} \mid \neg \mathrm{M} \& \mathrm{~T}^{j-1}\right)=\int_{0 \leq x \leq 1} x \mathrm{dG}$
} 
Putting this more intuitively: suppose that you think that each witness has some unknown chance of testifying positively to $M$ given that $M$ has not occurred. And suppose that if you know that $\mathrm{M}$ has indeed not occurred, observation of some uniform run of positive testimonies raises your estimate of this chance for the next witness, in the sense that for any $n$ strictly between 0 and 1, a little of your credence that this chance does not exceed $n$ gets shifted to the hypothesis that it does exceed $n$. (So if e.g. you were $50 / 50$ that the witness has at least $25 \%$ chance of delivering false positive testimony given $\neg \mathrm{M}$, you now become slightly more than 50/50 confident that the witness has at least this chance of giving this testimony.) Then this is already enough to ensure falsepositive projectibility. And exactly parallel arguments apply to true-positive projectibility.

(b) But if we are given true-positive and false-positive projectibility then we must reject ITP and IFP i.e. premises (4) and (5). More particularly: if true-positive projectibility is true then ITP is false; and if false-positive projectibility is true then IFP is false. ${ }^{17}$ This makes intuitive sense. For instance, if your having duped witness 1

-where $\mathrm{F}(x)=_{\text {def. }} \mathrm{F}_{\neg \mathrm{M}}^{j}(x)$ as defined at $(15)$ and $\mathrm{G}(x)=_{\text {def. }} \mathrm{F}_{\neg \mathrm{M}}^{j}\left(x \mid \mathrm{T}^{j-1}\right)$. Integration by parts on the corresponding indefinite integrals gives:

$$
\begin{aligned}
& \text { (iii) } \int x \mathrm{dF}=x \mathrm{~F}-\int \mathrm{F} \mathrm{d} x \\
& \text { (iv) } \int x \mathrm{dG}=x \mathrm{G}-\int \mathrm{G} \mathrm{d} x
\end{aligned}
$$

Since $F(0)=G(0)=0$ and $F(1)=G(1)=1$, substituting (iii) into (i) and (iv) into (ii) gives:

$$
\begin{array}{ll}
\text { (v) } & \mathrm{Cr}\left(\mathrm{t}^{j} \mid \neg \mathrm{M}\right)=1-\int_{0 \leq x \leq 1} \mathrm{~F} \mathrm{~d} x \\
\text { (vi) } & \mathrm{Cr}\left(\mathrm{t}^{j} \mid \neg \mathrm{M} \& \mathrm{~T}^{j-1}\right)=1-\int_{0 \leq x \leq 1} \mathrm{G} \mathrm{d} x ; \text { hence: } \\
\text { (vii) } & \mathrm{Cr}\left(\mathrm{t}^{j} \mid \neg \mathrm{M} \& \mathrm{~T}^{j-1}\right)-\mathrm{Cr}\left(\mathrm{t}^{j} \mid \neg \mathrm{M}\right)=\int_{0 \leq x \leq 1}(\mathrm{~F}-\mathrm{G}) \mathrm{d} x
\end{array}
$$

(vii) follows by subtracting (v) from (vi); false-positive projectibility follows directly from (vii) and (16). The proof for true-positive projectibility is exactly parallel.

${ }^{17}$ To prove that true-positive projectibility is inconsistent with ITP is to prove that (13a) is inconsistent with (4). So suppose that (4) and (13a) are both true. Then letting $k$ range over integers $\geq 2$ we have:

(i) $\quad \forall k \leq \mathrm{N} \mathrm{Cr}\left(\mathrm{T}^{k} \mid \mathrm{M}\right)=\mathrm{Cr}\left(\mathrm{t}^{k} \& \mathrm{~T}^{k-1} \mid \mathrm{M}\right)$ by definition

(ii) $\quad \forall k \leq \mathrm{N} \mathrm{Cr}\left(\mathrm{T}^{k} \mid \mathrm{M}\right)=\mathrm{Cr}\left(\mathrm{t}^{k} \mid \mathrm{T}^{k-1} \& \mathrm{M}\right) \mathrm{Cr}\left(\mathrm{T}^{k-1} \mid \mathrm{M}\right)$ by (i)

(iii) $\quad \forall k \leq \mathrm{N} \mathrm{Cr}\left(\mathrm{T}^{k} \mid \mathrm{M}\right)>\mathrm{Cr}\left(\mathrm{t}^{k} \mid \mathrm{M}\right) \mathrm{Cr}\left(\mathrm{T}^{k-1} \mid \mathrm{M}\right)$ by (ii), (13a)

(iv) $\quad \operatorname{Cr}\left(\mathrm{T}^{\mathrm{N}} \mid \mathrm{M}\right)>\mathrm{Cr}\left(\mathrm{t}^{\mathrm{N}} \mid \mathrm{M}\right) \mathrm{Cr}\left(\mathrm{t}^{\mathrm{N}-1} \mid \mathrm{M}\right) \ldots \mathrm{Cr}\left(\mathrm{T}^{1} \mid \mathrm{M}\right)$ by N-1 applications of (iii)

(v) $\quad \operatorname{Cr}\left(\mathrm{T}^{\mathrm{N}} \mid \mathrm{M}\right)>\prod_{1 \leq i \leq \mathrm{N}} \mathrm{Cr}\left(\mathrm{t}^{i} \mid \mathrm{M}\right)$ by (iv), definition of $\mathrm{T}^{1}$

(vi) Contradiction by (v), (4)

There is an exactly parallel proof that (13b) negative projectibility is inconsistent with (5) IFP. 
confirms that you have duped witness 2 then their testimonies cannot have been probabilistically independent with respect to your credence function $\mathrm{Cr}$ (conditional on $\neg \mathrm{M})$. So the premises of the BHE argument fail.

Let me briefly summarize the drift of this section. I am claiming that (4) ITP and (5) IFP are generally unattainable because projectibility is generally true, at least for collections of human witnesses. I illustrated this in connection with the Panopticon. The point of that device was to give the BHE argument the best possible run for its money. It achieves this because as Millican in effect pointed out, realistic grounds for doubt about true independence are also grounds for rejecting (4) and (5); and the Panopticon is an artificial environment where there are no such grounds for rejecting true independence, at least not if those grounds are of a sort that we can ever rule out. But as we have seen, projectibility is plausibly true even in the Panopticon. So there are grounds to reject (4) and (5) that apply quite independently of one's confidence in the true independence of the witnesses.

I just said that the Panopticon is an environment where there are no realistic grounds for rejecting true independence if it ever obtains. The reader might feel uneasy about this, on the grounds that if projectibility and true independence $d o$ both hold then we appear to have a counterexample to the Causal or Parental Markov Condition (PMC), which says (roughly) that an event is probabilistically independent of its non-effects conditional on all of its direct causes (Bovens and Hartmann 2003, pp. 68-9). For distinct testimonies in the Panopticon seem to have just one direct cause, namely $\mathrm{M}$ (or $\neg \mathrm{M}$ ); but what projectibility implies is that these testimonies remain probabilistically correlated even conditional on M itself. So the PMC might seem to fail in the Panopticon, if projectibility and the true independence condition both hold good in it. But since the CMP is plausible, this might look like grounds for doubting true independence.

I do myself think that multiple witness testimony in the Panopticon is a counterexample to that condition, one that shares its structure with Cartwright's wellknown case (1999, p. 7). But this interpretation is perhaps not mandatory. Instead, we could say the following. In the Panopticon each witness $j$ 's testimony has two direct causal influences: (a) the alleged miracle, that is, the occurrence that $\mathrm{M}$ either describes or misdescribes - this cause is common to all; $\left(b_{j}\right)$ the tendency of that witness to 
describe the event in the miraculous terms envisaged - this cause is specific to each $j$ and its actual strength may in each case be quantified (as e.g. in (14) and (15)) by $\mathrm{Ch}\left(\mathrm{t}^{j} \mid \neg \mathrm{M}\right.$ ) if $\mathrm{M}$ is false, and by $\mathrm{Ch}\left(\mathrm{t}^{j} \mid \mathrm{M}\right)$ if $\mathrm{M}$ is true. Now the defender of the CMP might claim further that the $\left(b_{j}\right)$ 's themselves have a common cause, for instance some common inherited source of, or common environmental pressure leading to, the actual distribution of gullibility and receptivity to miracles amongst human beings. In that case there is an indirect common cause of the $\mathrm{t}^{j}$ other than $\mathrm{M} / \neg \mathrm{M}$ itself, so true independence as defined at (12) fails to hold, and the CMP is preserved.

I have nothing to say here against that interpretation; and I am content to accept the CMP for present purposes. But this has no tendency to reinforce the BHE argument against the present point. That point, which the Panopticon simply illustrates, was that there are quite general grounds for thinking that projectibility holds, however plausible it is that the witnesses are truly independent. On anything like the foregoing story, the CMP holds but there is never true independence amongst testimonies to $\mathrm{M}$ (at least not for human witnesses: see further sect. 5); and it remains the case that true independence holds in the Panopticon if it holds anywhere. More to the point, it remains the case that the reasons for expecting projectibility in the Panopticon apply quite generally. ${ }^{18}$ But if they do, then the anti-Humean independence assumptions, and so also the BHE argument itself, must quite generally fail.

\section{Projectibility and human nature}

Of course this doesn't mean that we should rest content with the neo-Humean argument. Its opponent is likely to raise at least the following two objections: (i) How sure can we

\footnotetext{
${ }^{18}$ In a little more detail: if human gullibility and receptivity to miracles each have a common source, then you would expect their degrees within individual agents to be correlated. Since this degree is unknown for any particular agent, each witness's false (true) positive will raise one's estimate of a false (true) positive from the next, and this implies false-positive (true-positive) projectibility. Similar arguments go through for any other attempt to defend CMP in the Panopticon. For instance, suppose you thought that M is not a direct cause of the testimony because there is an intermediate cause, namely the common visual evidence present to all witnesses. (This is implausible in the case where the witnesses are arranged in a circle, but waive that.) Then assuming $\neg \mathrm{M}$, since the liability of that evidence to mislead is unknown, one's estimate of it will rise with each successive false positive, thus ensuring false-positive projectibility. The same goes mutatis mutandis for true-positive projectibility. (This is what will happen, for instance, in Dietrich and List's (2004) model of jury decisions based on a common evidential corpus.) I am grateful to a referee for pressing the points discussed here and in the last three paragraphs of sect. 4 in the main text.
} 
be that true-positive and false-positive projectibility really do apply to arbitrary testimonial ensembles? (ii) Concede that that they do, and so abandon the premises of the BHE argument: still, couldn't an accumulation of projectible witness testimonies push rational confidence in $\mathrm{M}$ arbitrarily close to unity? I address (i) in this section and (ii) in section 6 .

What would it take for a collection of testimonies to fail to satisfy (say) falsepositive projectibility, with respect to some alleged miracle $\mathrm{M}$ and some credence function $\mathrm{Cr}$ ? The credence function would have to reflect the belief that some sequence of mistaken positive testimonies would not be any sort of evidence at all that the next witness testimony is also positive (and also mistaken).

What makes that implausible, and so makes projectibility plausible, is the combination of two facts concerning our beliefs about human testimonial ensembles.

(a) They are smeared: one is not completely confident in one's estimate of the reliability of any one witness. That is to say: there is no particular chance $x$ such that you are certain that the next witness has a chance of exactly $x$ of testifying positively to $M$, given $\mathrm{M}$, or such that you are certain that the next witness has a chance of exactly $x$ of testifying positively to M, given $\neg \mathrm{M}$. (A special case of this is that one is not certain that any witness is perfectly reliable.)

(b) They are correlated: if one knows that $\mathrm{M}$ (or if one knows that $\neg \mathrm{M}$ ), and one learns that this or that particular witness testified positively, that will increase one's estimate of the chances that any other witness will also testify positively given $\mathrm{M}$ (or given $\neg \mathrm{M}$ ): for any non-extreme $x$, one's confidence will increase that this other witness's chance of so testifying is at least $x .^{19}$

These two assumptions are enough to entail (16) and hence also false-positive projectibility (and a parallel point goes for true-positive projectibility). Are they plausible? (a) Smearing is presumably an inevitable consequence of more general and inevitable limitations on one's knowledge of one's fellows. And what makes (b) plausible is that we take human beings to be at least in some degree epistemically uniform. Human witnesses are similar enough to one another that the observed responses of some humans

\footnotetext{
${ }^{19}$ These claims are not independent—in fact (b) entails (a) — but I am separating them here in order to make my assumptions completely explicit.
} 
will always constitute some confirmation that unobserved others also respond in that way to that stimulus. For instance, the more witnesses this pretended miracle is observed to have fooled, the greater our confidence that it has fooled or will fool others that we have not observed.

For projectibility to fail therefore, it would be necessary to arrange for a collection of witnesses so diverse that we should not be prepared to make this inference. If one witness to a pretended miracle were an eighteenth-century Scotch diplomat, another an Aztec from before the time of Cortes, a third a prehistoric Aborigine - in that case it may be that the credulity of the first would not even slightly confirm credulity on the part of the second or the third.

Whether this is so will probably depend upon the attitude that you take towards the uniformity of humanity. If (like Hume ${ }^{20}$ ) you think that human beings are cognitively more or less alike at all times and places, then it is likely that you would expect the reaction of the Scotsman to have some remote bearing upon those of the Aztec and of the Aborigine. But if you think that their differences in genetic endowment and upbringing make the Scotsman and the Aztec as cognitively different as if they were of different species, then positive testimony from either (conditional on $\mathbf{M}$, or conditional on $\neg \mathbf{M}$ ) will perhaps give you no reason at all to expect positive testimony from the other. I cannot here enter into this nice question of philosophical anthropology; but the plausibility of (true-positive and false-positive) projectibility, and hence also of Hume's argument, depends upon our taking a—not implausible—stance upon it.

It's harder to maintain that stance (i.e. (b)) quite generally towards 'witnesses' that are not human beings, because collections of such witnesses might arise in ways that are far more various, and so far more uninformative about one another, than the mechanisms that produce human testimony could ever be. Suppose that a miracle M-let it be the spontaneous explosion of the Moon-is (according to our background theory) apt to leave a range of very different and independently produced kinds of natural i.e. non-testimonial traces $\mathrm{t}^{1}, \mathrm{t}^{2}, \ldots \mathrm{t}^{n}$. For instance $\mathrm{t}^{1}$ might describe certain abrupt tidal

\footnotetext{
20 'Mankind are so much the same, in all times and places, that history informs us of nothing new or strange in this particular' (1777, p. 83). For discussion see Evnine 1993.
} 
variations, $\mathrm{t}^{2}$ the appearance on the surface of the Earth of a very large amount of lunar rock, and $\mathrm{t}^{3}$ photographic traces of the event from satellite imagery.

We might easily, and rightly, be convinced that this miracle would produce these traces via mechanisms that were unrelated in two ways. First, their upshots might have no common cause other than $\mathrm{M}$ itself. For instance: the tidal variations would be caused by changes in the local gravitational field consequent on $\mathrm{M}$; the appearance of lunar rock would be caused by the ejection of matter consequent upon $\mathrm{M}$; and the photographic traces would be caused by the incidence of light or other electromagnetic radiation from M upon the satellites' sensory equipment. So we have true independence in this case.

But second and more importantly, these traces are plausibly conditionally independent in the sense of (4) and (5): if we already knew whether M has occurred, an abrupt variation in tidal patterns would do nothing further to increase our expectation of lunar matter on the surface of the Earth, or of satellite evidence of a large explosion. So in this case the evidential ensemble $\left\{t^{1}, t^{2}, t^{3}\right\}$ satisfies the independence conditions necessary for the BHE argument to apply when we do not know whether M has occurred.

So there is this difference between testimonial and non-testimonial traces of miracles: true-positive projectibility and false-positive projectibility are much more plausible for the former than for the latter. What explains that difference is this fact: if we learn that one kind of non-testimonial trace of $\mathrm{M}$ is misleading, this tells us nothing about whether misleading non-testimonial traces of other kinds exist. But if we learn that an illusionist has taken in some human witnesses, this gives us reason to expect that she has also taken in other human witnesses, precisely because the unreliability of the miraclereport-producing mechanisms in Alice does tell us at least a little bit about the unreliability of the miracle-report-producing mechanisms in Bob. This definite limitation on the neo-Humean argument does not, however, affect any version of it that is solely and explicitly directed — as here, and as in Hume's original essay— to individual human testimonies or to aggregates thereof. ${ }^{21}$

\footnotetext{
${ }^{21}$ Another limitation arises if we suppose that each witness either is reliable (and so tells the truth) or makes up some story completely at random i.e. causally independently of the source. This assumption informs one of Bovens and Hartmann's models of independent witnessing (2003, pp. 112-23). In that case true-positive projectibility would fail. Moreover $q=\mathrm{Cr}(\mathrm{t} \mid \neg \mathrm{M})$ would be very small, perhaps no bigger than $\mathrm{Cr}(\neg \mathrm{M})$ : after all, if some particular miracle $\mathrm{M}$ has not occurred, how likely is it that an unreliable witness would just randomly relate the occurrence of that very miracle and not any of the many other
} 
Summing up the discussion of this section: it would be possible to accumulate independent 'testimonies' of a miracle, and so to drive its probability arbitrarily close to 1 , if the witnesses were so variegated that the response of any of them to the miracle had (for us) no evidential bearing on the response of any other, except in so far as it bore on the fact itself: so that these testimonies would be evidentially independent given that the miracle has occurred, and also evidentially independent given that it hasn't. And it is easy to imagine this happening if 'testimonies' are allowed to take the form of diverse natural traces. So Hume's argument can never rule out the credibility of a miracle on the basis of such diverse natural traces. ${ }^{22}$

On the other hand, it is reasonable that one's prior credence function should impose a minimal uniformity upon human witnesses, so that according to it, the testimony of any human witness to a miracle will always have some evidential bearing on the response of any other witness, even given knowledge about whether the miracle was real. Given this additional premise, the neo-Humean may infer the (true-positive and false-positive) projectibility of any assembly of human testimonies, and so may also exclude their probabilistic independence in the sense that the BHE objection requires.

stories that he might have made up? Finally, witness agreement on $\mathrm{M}$ would then be strong evidence of witness reliability, because witnesses are much more likely to have agreed on the truth than to have agreed on a story that each made up at random (Lewis 1946, p. 346; cf. Bovens and Hartmann 2003, pp. 56ff.). But although that model is applicable to some real-life cases (e.g. multiple-choice questions on a TV quiz show), it seems inapplicable to the cases that interest us here. There (and as my own model reflects) every report, true or false, is causally influenced by the fact reported on. And many witnesses' wrongly agreeing on $\mathrm{M}$ need not be written off as a vastly improbable coincidence but may instead raise one's estimate of the level of cunning behind this particular illusion.

${ }^{22}$ I thank a referee for pointing out that this may cast a new Bayesian light on the 'variety-of-evidence' thesis. Philosophers of science have long appreciated that 'the confirmation of a hypothesis depends not only on the quantity of the favourable evidence available, but also on its variety; the greater the variety, the stronger the evidential support' (Hempel 1966, p. 34). One standard Bayesian account of this fact measures the variety of evidences $\mathrm{E}_{1}, \mathrm{E}_{2}, \ldots$ for a hypothesis $\mathrm{H}$ by the rate at which $\mathrm{Cr}\left(\mathrm{E}_{n} \mid \mathrm{E}_{1} \& \mathrm{E}_{2} \& \ldots \& \mathrm{E}_{n-1}\right)$ approaches 1 as $n$ increases, where all evidences $\mathrm{E}$ for $\mathrm{H}$ are assumed to satisfy $\mathrm{Cr}(\mathrm{E} \mid \mathrm{H})=1$. The smaller the rate of increase in $\mathrm{Cr}\left(\mathrm{E}_{n} \mid \mathrm{E}_{1} \& \mathrm{E}_{2} \& \ldots \& \mathrm{E}_{n-1}\right)$, the more various the evidences are then said to be (Howson and Urbach 1989, p. 114; Earman 1992, p. 78). It is then a very simple consequence of Bayes's Theorem that the slower the rate of increase, the more an ensemble of $n$ evidences $\mathrm{E}_{i}$ confirms $\mathrm{H}$, ceteris paribus (for an explication of which last expression see Bovens and Hartmann 2003, p. 104). One limitation of this approach is that it only covers the case where $\mathrm{Cr}\left(\mathrm{E}_{i} \mid \mathrm{H}\right)=1$ for all $i$. The approach in this paper suggests a Bayesian account that applies to the more usual case that $\mathrm{Cr}\left(\mathrm{E}_{i} \mid \mathrm{H}\right)<1$. It distinguishes two dimensions of evidential variety, namely the rate of increase of $\mathrm{Cr}\left(\mathrm{E}_{n} \mid \mathrm{E}_{1} \& \mathrm{E}_{2} \& \ldots \& \mathrm{E}_{n-1} \& \mathrm{H}\right)$ and that of $\mathrm{Cr}\left(\mathrm{E}_{n} \mid \mathrm{E}_{1} \& \mathrm{E}_{2} \& \ldots \& \mathrm{E}_{n-1} \& \neg \mathrm{H}\right)$; and the calculations in sect. 6 show how under certain assumptions the degree of confirmation depends on the relations between, and the absolute magnitudes of, these quantities. 


\section{Projectibility and the rate of learning}

But just because it is a plausible condition, projectibility (of either type) is also a weak requirement upon one's credence function. This raises the concern that even if we concede it - and so set aside the BHE argument - it might still be possible for a large enough collection of dependent positive testimonies to entail the credibility of a miracle.

Return to equation (9), which settles, quite independently of the independence assumptions (4) and (5), how to update one's odds on the miracle given $\mathrm{N}$ positive witness testimonies to it. To repeat:

(9) $\mathrm{O}\left(\mathrm{M} \mid \mathrm{T}^{\mathrm{N}}\right)=\mathrm{O}(\mathrm{M}) \mathrm{Cr}\left(\mathrm{T}^{\mathrm{N}} \mid \mathrm{M}\right) / \mathrm{Cr}\left(\mathrm{T}^{\mathrm{N}} \mid \neg \mathrm{M}\right)$

Expanding the credential expression $\mathrm{Cr}\left(\mathrm{T}^{\mathrm{N}} \mid \mathrm{M}\right)$ we have:

$$
\operatorname{Cr}\left(\mathrm{T}^{\mathrm{N}} \mid \mathrm{M}\right)=\operatorname{Cr}\left(\mathrm{t}^{\mathrm{N}} \mid \mathrm{T}^{\mathrm{N}-1} \& \mathrm{M}\right) \operatorname{Cr}\left(\mathrm{T}^{\mathrm{N}-1} \mid \mathrm{M}\right)
$$

Repeating this expansion for $\mathrm{N}-1, \mathrm{~N}-2, \ldots, 2$ witnesses gives:

$$
\operatorname{Cr}\left(\mathrm{T}^{\mathrm{N}} \mid \mathrm{M}\right)=\mathrm{Cr}\left(\mathrm{t}^{1} \mid \mathrm{M}\right) \prod_{2 \leq j \leq \mathrm{N}} \mathrm{Cr}\left(\mathrm{t}^{j} \mid \mathrm{T}^{j-1} \& \mathrm{M}\right)
$$

Similarly expanding the credential expression $\operatorname{Cr}\left(\mathrm{T}^{\mathrm{N}} \mid \neg \mathrm{M}\right)$ and substituting that expansion and (18) into (9) gives:

$$
\begin{aligned}
& \mathrm{O}\left(\mathrm{M} \mid \mathrm{T}^{\mathrm{N}}\right)= \\
& \mathrm{O}(\mathrm{M}) \prod_{1 \leq j \leq \mathrm{N}}\left\{\mathrm{Cr}\left(\mathrm{t}^{j} \mid \mathrm{T}^{j-1} \& \mathrm{M}\right) / \mathrm{Cr}\left(\mathrm{t}^{j} \mid \mathrm{T}^{j-1} \& \neg \mathrm{M}\right)\right\}
\end{aligned}
$$

-where $\mathrm{T}^{0}$ is the tautology.

We know (this being the point of the BHE argument) that testimonial independence in the sense of (4) and (5), together with the minimal reliability constraints (6)-(8), drives this quantity arbitrarily high as $\mathrm{N}$ increases. For $\mathrm{Cr}\left(\mathrm{t}^{j} \mid \mathrm{T}^{j-1} \& \mathrm{M}\right)$ and $\mathrm{Cr}$ 
$\left(\mathrm{t}^{j} \mid \mathrm{T}^{j-1} \& \neg \mathrm{M}\right)$ are then constant for all $j \geq 1$ and so stand in a fixed ratio; so the right hand side of (19) increases exponentially with $\mathrm{N}$.

But if the testimonies are true-positive and false-positive projectible (and so not true-positive or false-positive independent $)$ then we may expect that $\mathrm{Cr}\left(\mathrm{t}^{j} \mid \mathrm{T}^{j-1} \& \mathrm{M}\right)$ and $\mathrm{Cr}\left(\mathrm{t}^{j} \mid \mathrm{T}^{j-1} \& \neg \mathrm{M}\right)$ are both increasing functions of $\mathrm{j}$. And whilst it does not follow that the right hand side of (19) increases without limit as $\mathrm{N} \rightarrow \infty$, this is not something that we can rule out. It all depends upon exactly how quickly (a) $\mathrm{Cr}\left(\mathrm{t}^{j} \mid \mathrm{T}^{j-1} \& \mathrm{M}\right.$ ) and (b) $\mathrm{Cr}$ $\left(\mathrm{t}^{j} \mid \mathrm{T}^{j-1} \& \neg \mathrm{M}\right)$ increase with $j$.

Putting this more informally: it all depends upon the rates at which one induces (a) from observed true positives to future true positives (given M) and (b) from observed false positives to future false positives (given $\neg \mathrm{M}$ ). If, given the occurrence of the miracle, even a short run of testimonies to $M$ convinces one that the next witness will also testify to $M$, then the rate associated with (a) is high. If, given the non-occurrence of the miracle, even a short run of (this time mistaken) testimonies to $\mathrm{M}$ convinces one that the next witness will be similarly mistaken, then the rate associated with (b) is high.

Here is a more intuitive way to think about (19). Its right hand side is a product of $\mathrm{N}-1$ ratios of posterior probabilities and one ratio of prior probabilities (remember that $\mathrm{T}^{0}$ is the tautology, so $\mathrm{Cr}\left(x \mid \mathrm{T}^{0} \& \neg \mathrm{M}\right)$ represents the prior conditional credence $\mathrm{Cr}$ $(x \mid \neg \mathrm{M})$ ). The $j$ th factor in that product of ratios divides one's confidence that the next witness is positive, given $j-1$ true positives, by one's confidence that the next witness is positive, given $j-1$ false positives.

When the testimonies are projectible, both numerator and denominator in each such factor will increase with $j$. Projectibility is therefore consistent with - though it does not entail - an attenuation of the size of that ratio as one moves from each positive witness to the next. If the attenuation is fast enough, the product of the ratios does not approach $\infty$, so the posterior odds on $\mathrm{M}$ does not approach $\infty$, and so one's posterior confidence in $\mathrm{M}$ does not approach 1. Everything therefore depends on the attenuation (if any) in the ratio of posteriors at each step.

One possibility that vindicates the anti-Humean is that there is a non-trivial ceiling on how much one can learn from false positives, relative to how much one learns 
from true positives. More specifically, suppose that one's rate of learning from false positive testimony decelerates in such a way that for any $j$, one's confidence in the next testimony's being positive, given $j$ false positives, never exceeds a fixed proportion $1-\Delta$, $\Delta>0$, of one's confidence in the next testimony's being positive, given $j$ true positives. Or equivalently: over all possible values of $j$, there is some lower bound $\mathrm{K}>1$ to the ratio of $\mathrm{Cr}\left(\mathrm{t}^{j} \mid \mathrm{T}^{j-1} \& \mathrm{M}\right)$ to $\mathrm{Cr}\left(\mathrm{t}^{j} \mid \mathrm{T}^{j-1} \& \neg \mathrm{M}\right)$. That is:

$$
\exists \mathrm{K}>1 \forall \mathrm{j} \geq 2 \mathrm{Cr}\left(\mathrm{t}^{j} \mid \mathrm{T}^{j-1} \& \mathrm{M}\right) / \mathrm{Cr}\left(\mathrm{t}^{j} \mid \mathrm{T}^{j-1} \& \neg \mathrm{M}\right) \geq \mathrm{K}
$$

If (20) is true then the product on the right hand side of (19) increases at least as quickly as $\mathrm{K}^{\mathrm{N}}$, and so as $\mathrm{N} \rightarrow \infty$ one's posterior odds on $\mathrm{M}$ should increase without limit.

But (20) arguably makes one too slow to learn from false positives. In particular, since $\operatorname{Cr}\left(\mathrm{t}^{j} \mid \mathrm{T}^{j-1} \& \mathrm{M}\right) \leq 1$, it implies that there is some $\Delta>0$ such that $\mathrm{Cr}\left(\mathrm{t}^{j} \mid \mathrm{T}^{j-1} \wedge \mathrm{M}\right)$ never exceeds $1-\Delta$, however large $j$ gets. For instance, it may be that one would never be more than $99 \%$ confident that the next testimony will be positive, even given $\neg \mathrm{M}$ and also that every one of the $10^{100}$ testimonies so far observed have been false positives.

If we think of subjective probabilities in terms of betting rates (as in e.g. Jeffrey 2004, Ch. 1), this means that there are some odds at which you would never accept a bet that the next witness would testify positively to $\mathrm{M}$ if you knew that $\neg \mathrm{M}$, however much uniform testimony to $\mathrm{M}$ you had already observed. It is implausible that we are this conservative. After all, we routinely make bets with huge downsides on the basis of a good deal less evidence than $\mathrm{T}^{j-1} \& \neg \mathrm{M}$ constitutes, for large enough $j$. (Whenever you travel on an airliner you are betting your life on its not crashing: but there have certainly been far fewer than, say, $10^{15}$ safe flights since commercial aviation began; and there were 140 crashes in the year 2013 alone (Bureau of Aircraft Accident Archives 2014).) But even if correct, this observation only makes it plausible that we do not in fact conform our credence functions to (20), not that there would be anything irrational about doing so.

More generally, I cannot myself see that rationality dictates any particular rate of induction from observed to unobserved false positives or from observed to unobserved 
true positives. But we can speak a little more generally about what answers to those questions would settle things for or against the Humean position. Perhaps the most straightforward idea is the following, log-linear model of attenuation: every true (false) positive reduces the probability that the next witness is a false (true) negative by some constant discount factor $\alpha<1(\beta<1)$. ${ }^{23}$ So we have for $j>2$ :

$$
\begin{aligned}
& \operatorname{Cr}\left(\neg \mathrm{t}^{j} \mid \mathrm{T}^{j-1} \& \mathrm{M}\right)=\alpha \operatorname{Cr}\left(\neg \mathrm{t}^{j-1} \mid \mathrm{T}^{j-2} \& \mathrm{M}\right) \\
& \operatorname{Cr}\left(\neg \mathrm{t}^{2} \mid \mathrm{t}^{1} \& \mathrm{M}\right)=\alpha \operatorname{Cr}\left(\neg \mathrm{t}^{1} \mid \mathrm{M}\right) \\
& \operatorname{Cr}\left(\neg \mathrm{t}^{j} \mid \mathrm{T}^{j-1} \& \neg \mathrm{M}\right)=\beta \operatorname{Cr}\left(\neg \mathrm{t}^{j-1} \mid \mathrm{T}^{j-2} \& \neg \mathrm{M}\right) \\
& \operatorname{Cr}\left(\neg \mathrm{t}^{2} \mid \mathrm{t}^{1} \& \neg \mathrm{M}\right)=\beta \mathrm{Cr}\left(\neg \mathrm{t}^{1} \mid \neg \mathrm{M}\right)
\end{aligned}
$$

Writing $\mathrm{X}_{j}$ for $\mathrm{Cr}\left(\mathrm{t}^{j} \mid \mathrm{T}^{j-1} \& \mathrm{M}\right)$ and $\mathrm{Y}_{j}$ for $\mathrm{Cr}\left(\mathrm{t}^{j} \mid \mathrm{T}^{j-1} \& \neg \mathrm{M}\right)(j>2)$ simplifies (21) and (23) to:

$$
1-\mathrm{X}_{j}=\alpha\left(1-\mathrm{X}_{j-1}\right)
$$

$$
1-Y_{j}=\beta\left(1-Y_{j-1}\right)
$$

Since (25) and (26) hold for all $j>2$ it follows that for any such $j$ we have:

$$
\begin{aligned}
& \mathrm{X}_{j}=1-\alpha^{j-2}+\alpha^{j-2} \operatorname{Cr}\left(\mathrm{t}^{2} \mid \mathrm{t}^{1} \& \mathrm{M}\right) \\
& \mathrm{Y}_{j}=1-\beta^{j-2}+\beta^{j-2} \operatorname{Cr}\left(\mathrm{t}^{2} \mid \mathrm{t}^{1} \& \neg \mathrm{M}\right)
\end{aligned}
$$

\footnotetext{
${ }^{23}$ In fact the simplest possible hypothesis about updating would be the Bayes-Laplace rule of succession, according to which the probability that the $(m+1)$ th instance of some type meets a certain condition, given that the first $m$ do, is $(m+1) /(m+2)$. So we have $\operatorname{Cr}\left(\mathrm{t}^{j} \mid \mathrm{T}^{j-1} \& \mathrm{M}\right)=\operatorname{Cr}\left(\mathrm{t}^{j} \mid \mathrm{T}^{j-1} \& \neg \mathrm{M}\right)=j /(j+1)$ for $j \geq$ 1. But on that assumption, which is derived from a uniform prior on the underlying objective chances, we should in particular have $\mathrm{Cr}\left(\mathrm{t}^{1} \mid \mathrm{M}\right)=\mathrm{Cr}\left(\mathrm{t}^{1} \mid \neg \mathrm{M}\right)=p=q=0.5$, whence $\mathrm{O}\left(\mathrm{M} \mid \mathrm{T}^{\mathrm{N}}\right)=\mathrm{O}(\mathrm{M})$ for any $\mathrm{N}$. That is too easy a victory for the neo-Humean.
} 
(21)-(28) together with definitions (6) and (7) imply that for $j \geq 1$ :

$$
\mathrm{X}_{j}=1+\alpha^{j-1}(p-1)
$$

$$
\mathrm{Y}_{j}=1+\beta^{j-1}(q-1)
$$

Substituting (29) and (30) into (19) gives:

$$
\begin{aligned}
& \mathrm{O}\left(\mathrm{M} \mid \mathrm{T}^{\mathrm{N}}\right)= \\
& \mathrm{O}(\mathrm{M}) \prod_{0 \leq j \leq \mathrm{N}-1}\left\{1+\alpha^{j}(p-1)\right\} /\left\{1+\beta^{j}(q-1)\right\}
\end{aligned}
$$

Notice that (11) is the special case of (31) that we get under independence i.e. when $\alpha=$ $\beta=1$. True-positive and false-positive projectibility demand respectively that $\alpha<1$ and that $\beta<1$; and we can treat $\alpha$ and $\beta$ as measuring how slowly you learn from experience.

There is no straightforward way to calculate the right-hand side of (31). It multiplies the prior odds on the miracle by a ratio of what are called $q$-shifted factorials (Gasper and Rahmen 2004, p. 6). If for convenience we set $\alpha=\beta$ and $p=0.8, q=0.2$, and the prior odds on $\mathrm{M}$ at a million to one (so that $\mathrm{O}(\mathrm{M})=0.000001$ ), we can compute approximate values for $\mathrm{O}\left(\mathrm{M} \mid \mathrm{T}^{\mathrm{N}}\right)$ at different settings of $\mathrm{N}$. Bearing in mind that $\mathrm{O}$ $\left(\mathrm{M} \mid \mathrm{T}^{\mathrm{N}}\right)=\mathrm{Cr}\left(\mathrm{M} \mid \mathrm{T}^{\mathrm{N}}\right) / \mathrm{Cr}\left(\neg \mathrm{M} \mid \mathrm{T}^{\mathrm{N}}\right)$, this implies the following values for $\mathrm{Cr}\left(\mathrm{M} \mid \mathrm{T}^{\mathrm{N}}\right):^{24}$

\begin{tabular}{|c|c|c|c|c|}
\hline $\mathbf{N}$ & $\boldsymbol{\alpha}, \boldsymbol{\beta}=\mathbf{0 . 5}$ & $\boldsymbol{\alpha}, \boldsymbol{\beta}=\mathbf{0 . 8}$ & $\boldsymbol{\alpha}, \boldsymbol{\beta}=\mathbf{0 . 9 5}$ & $\boldsymbol{\alpha}, \boldsymbol{\beta}=\mathbf{0 . 9 9}$ \\
\hline 1 & 0.000004 & 0.000004 & 0.000004 & 0.000004 \\
\hline 10 & 0.000008 & 0.000073 & 0.007305 & 0.195546 \\
\hline
\end{tabular}

\footnotetext{
${ }^{24}$ In case the reader wishes to reproduce these results and those in Table 2: I computed them using the QPochhammer function on Wolfram Alpha, http://www.wolframalpha.com/. In (31) the multiplier of O (M) can be written as QPochhammer [1-p, $\alpha, \mathrm{N}] /$ QPochhammer $[1-q, \beta, \mathrm{N}]$; suppressing the N-term gives the result for $\mathrm{N}=\infty$. So for instance, to compute the value at row 2 in the final column of Table 1, evaluate QPochhammer $[0.2,0.99,10] /$ QPochhammer $[0.8,0.99,10]$. Multiply by $10^{-6}(=\mathrm{O}(\mathrm{M}))$. This gives $\mathrm{O}\left(\mathrm{M} \mid \mathrm{T}^{\mathrm{N}}\right)$. Finally evaluate $\mathrm{Cr}\left(\mathrm{M} \mid \mathrm{T}^{\mathrm{N}}\right)$ by means of the identity $\mathrm{Cr}\left(\mathrm{M} \mid \mathrm{T}^{\mathrm{N}}\right)=\mathrm{O}\left(\mathrm{M} \mid \mathrm{T}^{\mathrm{N}}\right) /\{1+\mathrm{O}$ $\left.\left(\mathrm{M} \mid \mathrm{T}^{\mathrm{N}}\right)\right\}$.
} 


\begin{tabular}{|c|c|c|c|c|}
\hline 100 & 0.000008 & 0.000010 & 0.974979 & 1.000000 \\
\hline$\infty$ & 0.000008 & 0.000010 & 0.976658 & 1.000000 \\
\hline
\end{tabular}

Table 1: Posterior probability of miracle with $N$ witnesses if $p=0.8$ and $q=0.2$

To illustrate the meaning of this table: the first column $(\alpha, \beta=0.5)$ represents the state in which one learns about the witnesses relatively quickly: were one to learn that the first witness was a false positive, that would halve one's confidence that the second witness was not a false positive; were one then to learn that the second witness was also a false positive, that would halve again one's confidence that the third witness was not a false positive, and so on. In this state, ten witness testimonies for $\mathrm{M}$ (and none against) raise one's confidence in $\mathrm{M}$ from about 1 in a million to about 8 in a million. But the addition of arbitrarily many witness testimonies for $\mathrm{M}$ does nothing to increase it much further. ${ }^{25}$

On the other hand, the final column $(\alpha, \beta=0.99)$ represents the state in which one learns very slowly: every additional false (true) positive only reduces by $1 \%$ one's confidence that the next witness is not a false (true) positive. In that state, 100 positive testimonies to the miracle make one practically certain that it has occurred.

Relaxing the assumption $\alpha=\beta$ we can also calculate the limiting credence in M.

\begin{tabular}{|c|c|c|c|c|}
\hline & $\alpha=\mathbf{0 . 5}$ & $\alpha=\mathbf{0 . 8}$ & $\alpha=\mathbf{0 . 9 5}$ & $\alpha=\mathbf{0 . 9 9}$ \\
\hline$\beta=0.5$ & 0.000008 & 0.000004 & 0.000000 & 0.000000 \\
\hline
\end{tabular}

${ }^{25}$ It may be worth contrasting this and the next limitative result with two from a neighbouring literature, that on the Condorcet Jury Theorem (CJT). The Classical CJT says that if each of N jurors has the same fixed chance $p>0.5$ of delivering a correct verdict, and if chance-analogues of ITP and IFP hold for these jurors, then the chance of a majority verdict's being correct approaches 1 as $\mathrm{N} \rightarrow \infty$ (see e.g. Dietrich and List 2004, p. 238). The conditional probabilities that this result concerns are the converses of those at issue here i.e. the former involve probabilities of composite verdicts given a state of the world, whereas here what is at issue is the state of the world given a (unanimous) composite verdict. Dietrich and List 2004 discusses the latter sort of limiting probability in a case where all jurors have access to the same evidence. Here both ITP and IFP are relaxed, and the paper shows that the probability of a given state of the world's being $\mathrm{X}$, given a unanimous verdict that it is $\mathrm{X}$ on common evidence $\mathrm{E}$, tends to the probability of $\mathrm{X}$ given that the evidence points to $\mathrm{X}$. This holds on the assumption that $\mathrm{E}$ and not $\mathrm{X}$ is the last common cause of the individual verdicts, which is plausible in courtroom scenarios but not e.g. in the Panopticon, where $\mathrm{M} / \neg \mathrm{M}$ plausibly is the last common cause of each of the $\mathrm{t}^{i}$. Finally, Ladha 1992 also considers cases where ITP and IFP fail. That paper establishes (different) lower limits on converses of the conditional probabilities described here, and describes these results in terms of objective correlation coefficients between the $\mathrm{t}^{i}$ rather than (as here) in terms of the subjective rate at which one learns from them. 


\begin{tabular}{|c|l|l|l|l|}
\hline $\boldsymbol{\beta}=\mathbf{0 . 8}$ & 0.000193 & 0.000010 & 0.000004 & 0.000000 \\
\hline $\boldsymbol{\beta}=\mathbf{0 . 9 5}$ & 0.999463 & 0.998991 & 0.976658 & 0.000002 \\
\hline $\boldsymbol{\beta}=\mathbf{0 . 9 9}$ & 1.000000 & 1.000000 & 1.000000 & 1.000000 \\
\hline
\end{tabular}

Table 2: posterior credence in $M$ with infinitely many witnesses

As this table shows, if one learns very slowly and equally slowly from false positives and from true positives (e.g. $\alpha=\beta=0.99$ ), an accumulation of positive testimonies to $M$ will eventually make one practically certain of that miracle. But, if one learns very slowly, but slightly more quickly from false positives than from true positives (e.g. $\alpha=0.99, \beta=$ 0.95), arbitrarily many positive testimonies to $M$ have almost no effect on one's initial skepticism. Again, if one learns quickly from false positives and quickly from true positives (e.g. $\alpha=\beta=0.5$ ), then a very extensive collection of positive testimonies does little to confirm M. In that case, appealing to more and more causally independent witnesses to a miracle to assure yourself that it happened is about as futile as checking several copies of this morning's newspaper to assure yourself that what it said was true. ${ }^{26}$

So the model of credal updating that (21)-(24) encode encourages a somewhat equivocal conclusion. According to that model, there are perfectly rational initial states of belief in which no amount of positive witness testimony could ever get a non-witness to believe in the occurrence of a miracle, even though her initial credence in the miracle is neither zero nor infinitesimal. But there are others on which this certainly could happen. It all depends on the parameters $\alpha$ and $\beta$, the measures of how slowly you learn about your witnesses. Somebody who is willing to learn quickly ought to continue to be skeptical of the miracle however extensive the uniform testimony in its favour; but things are different if you are as doxastically conservative on this matter as $\alpha=\beta=0.99$ would imply. And there is no obvious rational mandate to prefer either stance.

\footnotetext{
${ }^{26}$ This example, which is Wittgenstein's (2009, sect. 265), corresponds to the case that $\alpha$ and $\beta$ are both close to zero: you are almost certain that what the first copy says is also what the second and all subsequent copies will say, whatever your confidence of its truth. In that case the product on the right hand side of (31) never gets much higher than $p / q$. So however many copies of the newspaper you check, your opinion on what it reports stays at roughly the point that it reached when you read the first copy.
} 


\section{Conclusion}

I therefore regret that the proper conclusion concerning the neo-Humean argument must be similarly ambivalent.

On the one hand, the initial BHE objection will fail if the independence conditions ITP and IFP fail, even for ensembles of witnesses that are known to satisfy Millican's true independence. And ITP and IFP $d o$ fail if true-positive and false-positive projectibility hold. And both forms of projectibility do hold if we assume even slight homogeneity amongst the witnesses.

On the other hand, even multiple projectible testimonies may drive the probability of the miracle arbitrarily close to one. Whether they do depends upon the rate at which we learn from some witnesses about others, concerning which a good deal remains to be said.

For instance, I have only cursorily considered the case in which $\alpha$ and/or $\beta$ change, perhaps at different rates, as one encounters more and more positive witnesses. (20) describes one way that could happen that would favour the anti-Humean. I have argued briefly against this model of variable $\beta$, but there are certainly others, and I could not argue against all of them a priori.

As a possible example of the latter, consider the anti-Humean case that might arise from causally related and possibly insincere testimonies in connection with a special kind of miracle: I mean, one that would motivate witnesses to testify to it even in face of strong disincentives. It might be, for instance, that people who testify to the miracle are put to death (as happened to the early Christians); knowing this would quite possibly give other witnesses strong incentives not to testify to $\mathrm{M}$, even if they believed it. But if the miracle is itself a sign of life after death for those who profess it, there is then a case that $\beta$, but perhaps not $\alpha$, should eventually (i.e. with increasing $j$ ) exceed unity: a long enough string of false positives might make one less confident that the $j$ th witness testifies positively, knowing as he does the fate of his $j-1$ predecessors. In that special case, the accumulation of witness testimony to $\mathrm{M}$ would speak even more potently for the truth of $\mathrm{M}$ itself than under the independence assumptions (4) and (5). ${ }^{27}$

\footnotetext{
${ }^{27}$ T. and L. McGrew apply this argument to the specific case of the resurrection of Jesus (2009, pp. 631-7). I cannot here give this point, or their elaboration of it, the extended discussion that both deserve. But it is
} 
So my arguments do not after all realize the 'everlasting check to all kinds of superstitious delusion' that Hume envisaged. But I think they do establish two things that are worth establishing. First, they show that the BHE argument is not any quick refutation of Hume. Second, they show that on more realistic assumptions than that argument allows, there are apparently quite reasonable prior distributions on which one should reject uniformly positive, truly independent and arbitrarily extensive testimony to a particular miracle. In addition, they indicate the lines of enquiry that we (I mean we Bayesians) should pursue in order to sort out those testimonial aggregates that might offer significant confirmation of miracle claims, from those that never could.

\section{References}

Babbage, Charles 1838: Ninth Bridgewater Treatise, second edition. London: John Murray. Excerpted in Earman 2000, pp. 203-12.

Bentham, Jeremy 1791: Panopticon. Dublin: T. Payne, repnt in Bozovic 1995. Bovens, Luc and Stephan Hartmann 2003: Bayesian Epistemology. Oxford: OUP. Bozovic, Miran (ed.) 1995. The Panopticon Writings. London: Verso.

Broad, Charles D. 1916: Hume's Theory of the Credibility of Miracles. Proceedings of the Aristotelian Society, 17, pp. 77-94.

Burks, Arthur W. (ed.) 1958: Collected Papers of Charles Sanders Peirce Vol. VII. Cambridge, MA: Harvard UP.

Cartwright, Nancy 1999: Causal Diversity and the Markov Condition. Synthese, 121, pp. $3-27$.

worth mentioning that even given these disincentives to positive testimony, one might still expect $j-1$ false positives to confirm a jth. (i) Given the hypothesized incentives, positive testimony is a strong sign that the testifier is very confident that $\mathrm{M}$ is true; and so $j-1$ positive testimonies should confirm the hypothesis that the $j$ th witness is also very confident in $\mathrm{M}$. But strong enough credence in $\mathrm{M}$ would lead you to expect testimony to $\mathrm{M}$ whether $\mathrm{M}$ is true or false. So via its bearing on the witness's belief, his false positive makes a positive contribution through this route to our expectation of future false positives (whether its net contribution is positive is a further question). (ii) There is evidence that members of a small group of like-minded individuals facing a common threat become more deeply committed to their common cause and more willing to take extreme risks for it (see e.g. McCauley and Moskalenko 2008, pp. 423f.). This being so, it would be reasonable to take a string of false positives from a group of interacting witnesses to make a positive contribution through this route to our confidence that the next witness is also positive. These considerations exert downward pressure on $\beta$. But what is necessary at this point is further empirical engagement with the McGrews' argument; that is best done in another place. 
Chandler, Jake and Victoria Harrison 2012: Probability in the Philosophy of Religion. Oxford: OUP.

Craig, William Lane and James Porter Moreland (ed.) 2009: Blackwell Companion to Natural Theology. Oxford: Blackwell.

Dawid, Philip and Anthony Gillies 1989: A Bayesian Analysis of Hume's Argument Concerning Miracles. Philosophical Quarterly, 39, pp. 57-65.

Dietrich, Franz and Christian List 2004: A Model of Jury Decisions where all Jurors have the Same Evidence. Synthese, 142, pp. 175-202.

Duncan, Simon and Antonia Lolordo (ed.) 2009: Debates in Modern Philosophy: Essential Readings and Contemporary Responses. London: Routledge.

Earman, John 1992: Bayes or Bust? A Critical Examination of Bayesian Confirmation Theory. Cambridge, Mass.: MIT Press.

2000: Hume's Abject Failure. Oxford: OUP.

2002: Bayes, Hume, Price and Miracles. In Swinburne 2002, pp. 91-109.

Evnine, Simon 1993: Hume, Conjectural History, and the Uniformity of Nature. Journal of the History of Philosophy, 31, pp. 589-606.

Fogelin, Robert 2003: A Defence of Hume on Miracles. Princeton: Princeton UP.

Gaspar, George and Mizan Rahmen 2004: Basic Hypergeometric Series. Cambridge: CUP.

Hempel, Carl G. 1966: Philosophy of Natural Science. Englewood Cliffs, N. J.: PrenticeHall.

Holder, Rodney 1998: Hume on miracles: Bayesian Interpretation, Multiple Testimony and the Existence of God. British Journal for the Philosophy of Science, 49, pp. 49-65.

Howson, Colin and Peter Urbach. 1989. Scientific Reasoning: the Bayesian Approach. Open Court: La Salle, Ill.

Hume, David 1777: Enquiries Concerning Human Understanding and Concerning the Principles of Morals, rpnt 1975, ed. L. A. Selby-Bigge. Oxford: Clarendon Press.

Jantzen, Benjamin C. 2012: Peirce on Miracles. In Chandler and Harrison 2012, pp. 2745.

Jeffrey, Richard C. 2004: Subjective Probability: The Real Thing. Cambridge: CUP. Joyce, James 1999: Foundations of Causal Decision Theory. Cambridge: CUP. 
Kruskal, William 1988: Miracles and Statistics: the Casual Assumption of Independence. Journal of the American Statistical Association, 83, pp. 929-940.

Ladha, Krishna K. 1992: The Condorcet Jury Theorem, Free Speech, and Correlated Votes. American Journal of Political Science 36, pp. 617-34.

Lewis, Clarence I. 1946: An Analysis of Knowledge and Valuation. La Salle: Open Court. McCauley, Clark and Sophia Moskalenko. 2008. Mechanisms of Political Radicalization: Pathways Toward Terrorism. Terrorism and Political Violence 20, pp. 415-433.

McGrew, Timothy and Lydia McGrew 2009: The Argument from Miracles: a Cumulative Case for the Resurrection of Jesus of Nazareth. In Craig and Moreland 2009, pp. 593-662.

Mackie, John L. 1982: The Miracle of Theism: Arguments for and against the Existence of God. Oxford: OUP.

Merrill, Kenneth R. 1991: Hume's 'Of Miracles', Peirce, and the balancing of likelihoods. Journal of the History of Philosophy, 29, pp. 85-113.

Millican, Peter 2003: Hume, Miracles and Probabilities: Meeting Earman's Challenge, <http://www.davidhume.org/papers/millican/2003\%20Hume\%20Miracles\%20Probabili

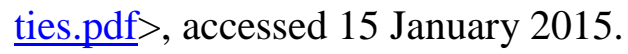

2011: Twenty Questions about Hume's 'Of Miracles'. Royal Institute of Philosophy Supplement, 68, pp. 151-92.

2013: Earman on Hume on Miracles. In Duncan and Lolordo 2013, pp. 271-83.

Peirce, Charles S. 1901: The Logic of Drawing History from Ancient Documents. In Burks 1958, pp. 89-164.

Sobel, Jordan Howard 2004: Logic and Theism: Arguments For and Against Beliefs in God. Cambridge: CUP.

Sober, Eliot: 1991. Reconstructing the Past: Parsimony, Evolution and Inference. Bradford: MIT Press.

2004: A Modest Proposal. Philosophy and Phenomenological Research, 68, pp. 487-94.

Swinburne, Richard (ed.) 2002: Bayes's Theorem. Oxford: OUP/British Academy. 
Wittgenstein, Ludwig 2009 [1951]: Philosophical Investigations. Tr. G. E. M. Anscombe, P. M. S. Hacker and J. Schulte. Revised 4th ed. by P. M. S. Hacker and J. Schulte. Malden: Wiley-Blackwell. 